\title{
Long-term results of screening with magnetic resonance imaging in women with BRCA mutations
}

\begin{abstract}
K Passaperuma', E Warner*,', PA Causer², KA Hill', S Messner ${ }^{3}$, JW Wong ${ }^{4}$, RA Jong ${ }^{2}$, FC Wright ${ }^{5}$, MJ Yaffe ${ }^{6}$, EA Ramsay ${ }^{6}$, S Balasingham', L Verity', A Eisen', B Curpen ${ }^{2}$, R Shumak $^{7}$, DB Plewes $^{6}$ and SA Narod ${ }^{8}$

'Department of Medicine, Division of Medical Oncology, Sunnybrook Health Sciences Centre, University of Toronto, 2075 Bayview Avenue, Toronto, Ontario, Canada M4N 3M5; ²Department of Medical Imaging, Sunnybrook Health Sciences Centre, University of Toronto, 2075 Bayview Avenue, Toronto, Ontario, Canada M4N 3M5; ${ }^{3}$ Division of Preventative Oncology, Sunnybrook Health Sciences Centre, University of Toronto, 2075 Bayview Avenue, Toronto, Ontario, Canada M4N 3M5; ${ }^{4}$ Department of Anatomic Pathology, Sunnybrook Health Sciences Centre, University of Toronto, 2075 Bayview Avenue, Toronto, Ontario, Canada M4N 3M5; ${ }^{5}$ Department of Surgery, Division of General Surgery, Sunnybrook Health Sciences Centre, University of Toronto, 2075 Bayview Avenue, Toronto, Ontario, Canada M4N 3M5; ' Department of Medical Biophysics, Imaging Research, Sunnybrook Health Sciences Centre, University of Toronto, 2075 Bayview Avenue, Toronto, Ontario, Canada M4N 3M5; 7 OBSP Cancer Care Ontario, 505 University Avenue, Toronto, Ontario, Canada M5G IX3; ${ }^{8}$ Women's College Research Institute, University of Toronto, 790 Bay Street, Toronto, Ontario, Canada M5G IN8
\end{abstract}

BACKGROUND: The addition of breast magnetic resonance imaging (MRI) to screening mammography for women with BRCA mutations significantly increases sensitivity, but there is little data on clinical outcomes. We report screening performance, cancer stage, distant recurrence rate, and breast cancer-specific mortality in our screening study.

METHODS: From 1997 to 2009, 496 women aged 25 to 65 years with a known BRCA//2 mutation, of whom 380 had no previous cancer history, were enrolled in a prospective screening trial that included annual MRI and mammography.

RESULTS: In 1847 screening rounds, 57 cancers were identified (53 screen-detected, I interval, and 3 incidental at prophylactic mastectomy), of which 37 (65\%) were invasive. Sensitivity of MRI vs mammography was $86 \%$ vs $19 \%$ over the entire study period $(P<0.000 \mathrm{I})$, but was $74 \%$ vs 35\% from 1997 to $2002(P=0.02)$ and $94 \%$ vs $9 \%$ from 2003 to $2009(P<0.000$ I $)$, respectively. The relative sensitivities of $\mathrm{MRI}$ and mammography did not differ by mutation, age, or invasive vs non-invasive disease. Of the incident cancers, $97 \%$ were Stage 0 or 1 . Of 28 previously unaffected women diagnosed with invasive cancer, I BRCA I mutation carrier died following relapse of a $3 \mathrm{~cm}$, node-positive breast cancer diagnosed on her first screen at age 48 (annual breast cancer mortality rate $=0.5 \%$ ). Three patients died of other causes. None of the 24 survivors has had a distant recurrence at a median follow-up of 8.4 years since diagnosis.

CONCLUSION: Magnetic resonance imaging surveillance of women with BRCA / /2 mutations will detect the majority of breast cancers at a very early stage. The absence of distant recurrences of incident cancers to date is encouraging. However, longer follow-up is needed to confirm the safety of breast surveillance.

British Journal of Cancer (2012) I 07, 24-30. doi:I0.1038/bjc.2012.204 www.bjcancer.com

Published online 15 May 2012

(c) 2012 Cancer Research UK

Keywords: breast cancer; BRCA//2 mutation; magnetic resonance imaging; mammography; screening; sensitivity and specificity

In women with a $B R C A 1$ or $B R C A 2$ gene mutation, the risk of breast cancer is low until the age of 25 , but by age 70 , the cumulative risk reaches $57-65 \%$ for $B R C A 1$ and $45-49 \%$ for BRCA2 mutations (Antoniou et al, 2003; Chen and Parmigiani, 2007). Options for managing this risk include bilateral prophylactic mastectomy (Hartmann et al, 1999) or surveillance. Over the past decade, several studies have demonstrated that annual magnetic resonance imaging (MRI) is a significantly more sensitive screening modality than annual mammography (Kriege et al, 2004; Warner et al, 2004; Kuhl et al, 2005; Lehman et al, 2005; MARIBS study group, 2005; Hagen et al, 2007; Lehman et al, 2007;

*Correspondence: Dr E Warner; E-mail: ellen.warner@sunnybrook.ca Received 8 December 2011; revised 12 April 2012; accepted 18 April 2012; published online 15 May 2012
Warner et al, 2008; Rijnsburger et al, 2010; Sardanelli et al, 2011). However, if MRI screening is to be a reasonable alternative to prophylactic mastectomy, it is necessary that breast cancer mortality in women who undergo annual screening be similar to that of women who choose prophylactic surgery. To date, no randomised study has compared the mortality of women undergoing MRI with women undergoing mammography (or who undergo prophylactic mastectomy). As such a study will likely never be done in women with $B R C A$ mutations, indirect evidence is necessary to support a recommendation for long-term screening. Convincing evidence would include: a very low interval cancer rate, a very low incidence of invasive tumours greater than stage I, and a very low rate of distant recurrence.

It is unclear to what extent the sensitivity of MRI compared with mammography varies by age or mutation type. It has been suggested that MRI may not be necessary in women over age 50 
(National Institute for Health and Clinical Excellence (NICE), 2006) or that annual screening may not be frequent enough in young women with BRCA1 mutations (Tilanus-Linthorst et al, 2007; Shah et al, 2009; Rijnsburger et al, 2010).

Between 1997 and 2009, we screened 496 women with BRCA1 or BRCA2 mutations using annual MRI and mammography. We report the sensitivities of MRI and mammography by age and mutation type, as well as clinical outcomes, including cancer stage, systemic therapy, distant recurrence, and survival.

\section{PATIENTS AND METHODS}

Detailed results of the study population and protocol have been published previously (Warner et al, 2004) and are summarised below.

\section{Study population}

Between 1 November 1997 and 30 June 2009, women aged 25 to 65 with a known $B R C A 1$ or $B R C A 2$ mutation, and at least one breast in which cancer had never been diagnosed, were enrolled consecutively in a prospective breast cancer screening trial at a single tertiary centre. Ethics approval was obtained by the institutional review board and all participants provided informed consent. Women who were pregnant or lactating were asked to defer participation until they were 4-6 months past weaning (or 4-6 months post-partum if not breastfeeding). Similarly, women on study who became pregnant discontinued screening until 4-6 months after delivery or weaning. Women were advised to stop breastfeeding after 6 months post-partum or 18 months from their last screening, whichever was earlier. Before 2004, women with a prior history of breast or ovarian cancer were eligible for annual screening for 3 years, and all others for 5 years, after which screening was continued off study by the referring physician. From 2004 onwards, only unaffected women were eligible and were offered annual screening until the study ended in June 2009. These women were then referred to a centre that provided clinical MRI screening to continue screening off study. Women diagnosed with breast cancer on study continued screening on study unless they underwent bilateral prophylactic mastectomy.

\section{Screening protocol}

Eligible women were screened annually with conventional fourview film screen mammography, dynamic gadolinium contrastenhanced MRI, and ultrasound, and screened semi-annually with clinical breast examination. All imaging modalities were performed on the same day. Screening was performed during the second week of the menstrual cycle in premenopausal women to minimise the occurrence of breast densities or physiological enhancement related to cyclical hormonal variation. Enhanced MRI techniques were continually incorporated throughout the study. Digital mammography was introduced in January 2008. Ultrasound screening was discontinued in May 2005, because of inadequate sensitivity and specificity. All imaging studies were read independently by a radiologist specialised in breast imaging, and classified using the American College of Radiology Breast Imaging Reporting and Data System (BI-RADS) as follows: 0 -further information or workup required; 1-negative; 2-benign finding; 3-probable benign finding (short follow-up interval required); 4-suspicious abnormality; 5-highly suggestive of malignancy (Kopans et al, 1993).

\section{Biopsies}

A biopsy was performed if at least one imaging modality was scored as BI-RADS 4 or 5 . If the MRI screening test was abnormal
(BI-RADS score 3-5), but no other modality was abnormal, then a diagnostic MRI procedure was performed approximately 4 weeks later. Cases that were suspicious for malignancy on diagnostic MRI examination (BI-RADS score 4 or 5) proceeded to biopsy. BI-RADS 3 lesions were not routinely biopsied, but were followed up with MRI 6 months, 1 year, and 2 years after the initial imaging study. Whenever possible, core and excisional biopsies were performed under ultrasound or stereotactic guidance. For MRIonly visualised BI-RADS 4 and 5 lesions, excisional biopsy was initially performed using an MRI-guided wire localisation technique. From January 2003 onwards, whenever technically feasible, percutaneous MRI-guided biopsies using 14-Gauge and 9-Gauge vacuum-assisted devices were performed (Daniel et al, 2001). Careful pathological review was performed by a pathologist with special expertise in breast cancer.

\section{Data collection and analysis}

Baseline demographic data were collected using a self-administered questionnaire at the time of study enrolment. Details of cancers detected on study were collected from electronic medical records and hospital charts. Treatment of women diagnosed with breast cancer was at the discretion of the treating physician. Follow-up data were obtained from a self-administered questionnaire mailed annually to all women who had undergone at least one round of MRI screening on study, whether or not they were continuing to be screened on the study. The questionnaire recorded new diagnoses of breast cancer and recurrences, as well as prophylactic mastectomies. The follow-up data reported here is accurate as of 1 March 2012. Women for whom the date of last follow-up was before 1 January 2010 were considered lost to follow-up. Women were taken off study for protocol violation if there was a 24-month or greater interval between any two rounds of screening.

Cancers diagnosed more than 1 year after the last study MRI screen were not included in the analysis. Multicentric tumours in one breast were considered a single cancer and the size of the largest invasive component was reported. The sensitivity of a given modality was defined as the number of (biopsy-proven) cancers detected by that modality (based on BI-RADS score $0,3-5$ ) divided by the total number of cases detected by all modalities, plus interval cases, and incidental cancers found at the time of prophylactic mastectomy in the 1-year period following the last screen. Sensitivity results of the initial study phase from 1997-2002 (Warner et al, 2004) were compared with the final phase to assess changes over time. The specificity of a given modality was defined as the number of true-negative screens divided by the sum of truenegative and false-positive screens (i.e., screens scored BI-RADS 0 , 3-5 leading to either a benign biopsy or close imaging follow-up with no progression for at least 2 years). Cancers were divided into ductal carcinoma in situ without micro-invasion, ductal carcinoma in situ with micro-invasion (defined as invasive tumour measuring $\leqslant 1 \mathrm{~mm}$ in greatest dimension), and invasive cancer. Ductal carcinoma in situ with and without micro-invasive disease were combined into a single category (DCIS). Fisher's exact tests and $t$ tests were used for categorical and continuous variables, respectively, with a two-sided $P$-value of less than 0.05 considered to be statistically significant.

\section{RESULTS}

A total of 496 women (267 BRCA1 and 229 BRCA2 mutation carriers) completed from 1 to 9 rounds of screening (median 3 ), for a total of 1847 rounds (Table 1). The median age at first screen was 44 years (range 25 to 66 years). A total of 90 women had a past history of breast cancer and 29 women had a past history of ovarian cancer. The median time from study entry to last follow-up 
for the cohort of 496 women was 7.6 years, with 35 women (7\%) lost to follow-up. None of the participants who were diagnosed with breast cancer were lost to follow-up.

Overall, 57 breast cancers (53 screen-detected, 1 interval, and 3 detected incidentally at the time of prophylactic mastectomy) were diagnosed in 54 women whose median age was 48 years (range 32 to 68 years). Of these 54 women, 11 had a prior diagnosis of breast cancer and 2 women had a prior diagnosis of ovarian cancer. A single interval cancer was detected in a 40-year-old BRCA1 mutation carrier 8 months after her last negative screen, yielding an interval cancer rate of $2 \%$ overall and $3 \%$ for the BRCA1 cohort. The cancer was a palpable, $1.7 \mathrm{~cm}$ 'triple-negative', grade 3 , nodenegative invasive ductal carcinoma. Two of the cancers detected at prophylactic mastectomy were DCIS, found 1 and 2 months after

Table I Baseline demographics by entire cohort $(n=496)$ and mutation status

\begin{tabular}{|c|c|c|c|}
\hline \multirow[b]{2}{*}{ Characteristic } & \multicolumn{3}{|c|}{ No. of participants } \\
\hline & $\begin{array}{c}\text { BRCAI } \\
(n=267)\end{array}$ & $\begin{array}{c}B R C A 2 \\
(n=229)\end{array}$ & $\begin{array}{l}\text { Total } \\
\text { (\%) }\end{array}$ \\
\hline \multicolumn{4}{|c|}{ Age at first study screen, years } \\
\hline$<30$ & 13 & 13 & $26(5)$ \\
\hline $30-39$ & 93 & 60 & $153(31)$ \\
\hline $40-49$ & 89 & 94 & $183(37)$ \\
\hline $50-59$ & 62 & 50 & $112(23)$ \\
\hline$\geqslant 60$ & 10 & 12 & $22(4)$ \\
\hline $\begin{array}{l}\text { Prior breast or ovarian } \\
\text { cancer }\end{array}$ & 66 & 53 & $116(23)$ \\
\hline \multicolumn{4}{|l|}{ Rounds of screening } \\
\hline Median (range) & $4(1-9)$ & $3(1-9)$ & $3(1-9)$ \\
\hline One & 43 & 46 & $89(16)$ \\
\hline Two & 35 & 30 & $65(13)$ \\
\hline Three or more & 189 & 153 & $342(70)$ \\
\hline
\end{tabular}

the last MRI. In one case, MRI had detected a $0.9-\mathrm{cm}$ area of clumped enhancement that was stable over 1 year (BI-RADS score 3 ), which was biopsied and found to be benign. The contralateral breast had a similar appearance on MRI, but was much larger in size, and was biopsy-proven DCIS for which the participant elected to undergo bilateral mastectomy, at which time a $1-\mathrm{cm}$ focus of DCIS was found in the breast with a prior benign biopsy. In the second case, a $0.2-\mathrm{cm}$ focus of DCIS found on prophylactic mastectomy was missed on preceding MRI (scored BI-RADS 2). Neither case was seen retrospectively on mammography. The third case was a $0.6-\mathrm{cm}$ invasive, node-negative ductal cancer diagnosed in a 36-year-old BRCA1 mutation carrier 6 months after her last screen. The tumour could not be visualised retrospectively on either MRI or mammography.

The 53 screen-detected breast cancers were detected in 1847 screening rounds (detection rate $2.9 \%$ ). The detection rate was $0 \%$ for women aged 25-29 ( 0 of 59 screens), $2.4 \%$ for women aged $30-49$ (28 of 1188 screens), $3.8 \%$ for women aged 50-59 (18 of 479 screens), and $5.8 \%$ for women aged 60 or more (7 of 121 screens).

\section{Screening performance}

Of the 57 diagnosed cancers, 49 (86\%) were detected by MRI and $11(19 \%)$ were detected by mammography $(P<0.0001)$. Only two cancers were detected by mammography and not by MRI. Both of these were diagnosed before 2001, and both were DCIS (one with micro-invasion). Two cases were detected by ultrasound only, before 2003 . Of the 37 invasive cancers, $89 \%$ were detected by MRI and $22 \%$ were detected by mammography $(P<0.0001)$. For the 20 cases of DCIS (4 with micro-invasion), sensitivities of MRI and mammography were $80 \%$ and $15 \%$, respectively $(P<0.0001)$. The observed sensitivities for mammography and MRI are presented in Table 2, according to time period, mutation type, age at diagnosis, and invasive status. The sensitivity of MRI improved over time (74\% vs $94 \%, P=0.05)$, whereas the sensitivity of mammography declined (35\% vs 9\%, $P=0.02)$. Higher sensitivity of mammography was seen with increasing tumour size but not with older patient age. The sensitivity of mammography was low for both

Table 2 Sensitivities of MRI and mammography

\begin{tabular}{|c|c|c|c|c|c|c|}
\hline \multirow[b]{2}{*}{ Characteristic } & \multicolumn{3}{|c|}{ All cancers ${ }^{\mathrm{a}}(\%)$} & \multicolumn{3}{|c|}{ Invasive cancers ${ }^{\mathrm{b}}(\%)$} \\
\hline & MRI & Mammography & $P$-values & MRI & Mammography & $P$-values \\
\hline BRCAI & $28 / 31(90)$ & $6 / 31(19)$ & $<0.0001$ & $21 / 23(91)$ & $6 / 23(26)$ & $<0.000 \mid$ \\
\hline BRCA2 & $20 / 25(80)$ & $5 / 25(20)$ & $<0.000$ I & $12 / 14(86)$ & $2 / 14(14)$ & 0.0004 \\
\hline \multicolumn{7}{|l|}{ Time period } \\
\hline \multicolumn{7}{|l|}{ Age at diagnosis } \\
\hline$<40$ & $9 / 12(75)$ & $3 / 12(25)$ & 0.04 & $5 / 6(83)$ & 2/6 (33) & 0.2 \\
\hline $40-49$ & $17 / 20(85)$ & $4 / 20(20)$ & $<0.000 \mid$ & $12 / 14(86)$ & $3 / 14(21)$ & 0.002 \\
\hline$\geqslant 50$ & $23 / 25(92)$ & $4 / 25(16)$ & $<0.0001$ & $16 / 17(94)$ & $3 / 17(18)$ & $<0.000$ \\
\hline \multicolumn{7}{|l|}{ Screening round } \\
\hline$>0.1-0.5$ & & & & $8 / 8(100)$ & $0 / 8(0)$ & 0.0002 \\
\hline$>0.5-1.0$ & & & & $16 / 18(89)$ & $4 / 18$ (22) & 0.0001 \\
\hline$>1.0-2.0$ & & & & $8 / 10(80)$ & $4 / 10(40)$ & 0.17 \\
\hline$>2.0$ & & & & I/I (100) & $0 / 1(0)$ & 1.0 \\
\hline
\end{tabular}

Abbreviation: $\mathrm{MRI}=$ magnetic resonance imaging. ${ }^{a}$ Includes three cancers detected incidentally at risk-reducing mastectomy. ${ }^{\mathrm{b}}$ Includes one cancer detected incidentally at risk-reducing mastectomy. 
Table 3 Comparison of screen-detected cancers by modality of detection $(n=5 \mathrm{I})^{\mathrm{a}}$

\begin{tabular}{|c|c|c|c|}
\hline \multirow[b]{2}{*}{ Characteristic } & \multicolumn{3}{|c|}{ No. of cancers detected } \\
\hline & $\begin{array}{c}\text { MRI and } \\
\text { mammography }\end{array}$ & $\begin{array}{l}\text { MRI } \\
\text { only }\end{array}$ & $\underset{\text { only }}{\text { Mammography }}$ \\
\hline $\begin{array}{l}\text { Total no. of cancers } \\
\text { detected }(\%)\end{array}$ & $9(18)$ & $40(78)$ & $2(4)$ \\
\hline Detected on first screen & 4 & 16 & । \\
\hline $\begin{array}{l}\text { Mean age at diagnosis, } \\
\text { years (range) }\end{array}$ & $46(34-54)$ & $\begin{array}{c}49 \\
(32-68)\end{array}$ & $45(39-51)$ \\
\hline \multicolumn{4}{|l|}{ Tumour size $(\mathrm{cm})$} \\
\hline DCIS & 1 & 12 & I \\
\hline$\leqslant 0.1$ (micro-invasive) & 0 & 3 & । \\
\hline $0.1-0.5$ & 0 & 8 & 0 \\
\hline$>0.5-1.0$ & 4 & 12 & 0 \\
\hline$>1.0-2.0$ & 4 & 4 & 0 \\
\hline$>2.0$ & 0 & I & 0 \\
\hline Node-positive & 0 & 3 & 0 \\
\hline \multicolumn{4}{|l|}{ Grade of invasive cancers } \\
\hline I & 0 & 3 & 0 \\
\hline 2 & 3 & 14 & 0 \\
\hline 3 & 5 & 9 & 0 \\
\hline
\end{tabular}

Abbreviations: $\mathrm{DClS}=$ ductal carcinoma in situ; $\mathrm{MRI}=$ magnetic resonance imaging. ${ }^{a}$ Total of $5 \mathrm{I}$ cancers, excluding 2 detected only by ultrasound (including a $1.9 \mathrm{~cm}$ invasive lobular cancer with I out of 17 lymph nodes positive), I interval cancer, and 3 incidental cancers.

BRCA1 (21\%) and BRCA2 (20\%) mutation carriers, whereas the sensitivity of MRI was high for both subgroups.

Table 3 compares the screen-detected cancers according to the modality with which they were detected. The average size of MRIdetected lesions was $1.16 \mathrm{~cm}$ (range $0.5-2 \mathrm{~cm}$ ) in the period from $1997-2002$ and $0.77 \mathrm{~cm}$ (range $0.03-3 \mathrm{~cm}$ ) in the period from 2003-2009 $(P=0.07)$. The average size of mammographically detected lesions was $1.3 \mathrm{~cm}$ (range $1-2 \mathrm{~cm}$ ) in the period from $1997-2002$ and $0.9 \mathrm{~cm}$ (range $0.7-1.2 \mathrm{~cm}$ ) in the period from 2003-2009 $(P=0.25)$.

The specificity of MRI was $90 \%$ overall ( $82 \%$ for the first screen and $93 \%$ for subsequent screens), and the specificity of mammography was $97 \%$ overall ( $96 \%$ for the first screen and $97 \%$ for subsequent screens).

\section{Tumour characteristics}

Of 57 cancers diagnosed, 31 occurred in $B R C A 1$ mutation carriers and 26 in BRCA2 carriers. Of these, 8 (26\%) were DCIS in BRCA1 mutation carriers ( 3 with micro-invasion) compared with $12(46 \%)$ in BRCA2 mutation carriers (1 with micro-invasion). The mean size of invasive cancers was $1.02 \mathrm{~cm}$ (range, $0.3-3 \mathrm{~cm}$ ). Table 4 compares the invasive cancers by mutation status. Cancers in $B R C A 1$ mutation carriers were significantly more likely to be hormone-receptor negative and to have been treated with chemotherapy. They also tended to be larger and high-grade. A greater proportion of DCIS cases in $B R C A 1$ mutation carriers had a micro-invasive component compared with BRCA2 mutation carriers ( $38 \%$ vs $8 \%, P=0.26)$.

Of the 34 incident cancers, all but one (97\%) was Stage 0 or 1 . The mean size of invasive cancers diagnosed on the initial screen (prevalent cancers) and cancers diagnosed on subsequent screens (incident cancers) was 1.15 (range $0.3-3 \mathrm{~cm}$ ) and $0.93 \mathrm{~cm}$ (range $0.4-2 \mathrm{~cm})$, respectively $(P=0.28)$. Three out of four node-positive cancers were prevalent. Of the invasive cancers, those diagnosed
Table 4 Comparison of invasive cancers in BRCA / and BRCA2 mutation carriers

\begin{tabular}{lccc}
\hline & \multicolumn{2}{c}{ No. of cancers (\%) } & \\
\cline { 2 - 3 } Characteristic & BRCA I (n=23) & BRCA2 (n= 14) & P-values \\
\hline Mean size, cm (range) & $1.1(0.3-3)$ & $0.89(0.4-2)$ & 0.29 \\
Nodal status & & & \\
$\quad$ Negative & $20(87)$ & $13(93)$ & \\
$\quad$ Positive & $3(13)$ & $1(7)$ & \\
ER-positive & & & \\
PR-positive & $8(35)$ & $12(86)$ & 0.006 \\
HER2-positive & $5(22)$ & $10(71)$ & 0.005 \\
Grade & $1(4)$ & $1(7)$ & 1 \\
I & & & \\
2 & $1(4)$ & $2(14)$ & \\
3 & $10(43)$ & $9(64)$ & \\
Chemotherapy given & $12(52)$ & $3(21)$ & \\
$\quad$ & & & \\
Yes & $14(61)$ & $3(21)$ & \\
No & $9(39)$ & $11(79)$ & \\
\hline
\end{tabular}

Abbreviations: $\mathrm{ER}=$ estrogen receptor; $\mathrm{PR}=$ progesterone receptor.

on the first screen were more likely to be treated with chemotherapy ( 9 of $15,60 \%)$, compared with incident cancers $(8$ of $22,36 \%)$; however, the difference was non-significant $(P=0.19)$.

\section{Disease status and survival}

Table 5 summarises the demographic, tumour, treatment, and follow-up details of all 41 previously unaffected carriers who were diagnosed with a total of 43 cancers on study. At last follow-up, 10 of 37 living participants had not undergone risk-reducing mastectomy. There were no cases of contralateral cancer diagnosed during the follow-up period. Two women with intermediate-grade DCIS, who had undergone breast-conserving therapy, developed ipsilateral, intermediate-grade, node-negative invasive cancers 3 and 6 years later, for which both women underwent bilateral mastectomies and did not require chemotherapy. Both cancers were mammographically occult and detected on MRI, remote from the initial sites of cancer, and thus favoured to represent second primary tumours. Another woman had ipsilateral recurrence of DCIS with micro-invasion 2 years later, for which she underwent bilateral mastectomies.

Excluding the micro-invasive cancers, there were 28 invasive breast cancers diagnosed in women with no previous history of breast or ovarian cancer at enrolment. One of these women, a BRCA1 mutation carrier, died of breast cancer 5 years after her initial diagnosis. This cancer was diagnosed on her first screen at age 48 and was $3 \mathrm{~cm}$ in size, with one of 13 lymph nodes involved. This single distant relapse and death among 28 previously unaffected mutation carriers diagnosed with invasive cancers represents an overall distant recurrence rate of $3.6 \%$ and annual breast cancer-specific mortality rate of $0.5 \%$. Three women died of other causes (suicide, primary peritoneal cancer, and ovarian cancer at 1,3, and 4 years following breast cancer diagnosis). None of the 24 surviving patients has had a distant recurrence at a median follow-up of 8.4 years since diagnosis.

\section{DISCUSSION}

In this study of 496 women with BRCA1 or BRCA2 mutations screened with annual MRI plus mammography, 54 developed breast cancer. We observed a very low proportion of interval 
Table 5 Detailed overview of previously unaffected carriers diagnosed with cancer

\begin{tabular}{|c|c|}
\hline Characteristic & $\begin{array}{l}\text { No. of participants } \\
(\%)\end{array}$ \\
\hline \multicolumn{2}{|l|}{ Patient characteristics $(n=4 I)$} \\
\hline \multicolumn{2}{|l|}{ Mutation-type } \\
\hline$B R C A /$ & $2 \mid(5 \mid)$ \\
\hline$B R C A 2$ & $20(49)$ \\
\hline Median age at first study screen, years (range) & $47(28-65)$ \\
\hline \multicolumn{2}{|l|}{ Menopausal status } \\
\hline Pre- & $19(46)$ \\
\hline Peri- & $2(5)$ \\
\hline Post- & $20(49)$ \\
\hline Ashkenazi Jewish ethnicity ${ }^{a}$ & $9(22)$ \\
\hline Tamoxifen use ${ }^{b}$ (ever) & I (2) \\
\hline Prior oophorectomy (bilateral) & $18(44)$ \\
\hline Median age at diagnosis (range) & $46(32-68)$ \\
\hline \multicolumn{2}{|l|}{ Tumour characteristics $(n=43)^{c}$} \\
\hline Diagnosed on first screening round & $15(35)$ \\
\hline Screen-detected cancers & $40(93)$ \\
\hline Interval cancers & I (2) \\
\hline $\begin{array}{l}\text { Incidental cancers found at prophylactic } \\
\text { mastectomy }\end{array}$ & $2(5)$ \\
\hline \multicolumn{2}{|l|}{ Tumour size $(\mathrm{cm})$} \\
\hline DCIS & $12(28)$ \\
\hline$\leqslant 0.1$ (micro-invasive) & $3(7)$ \\
\hline $0.1-0.5$ & $7(16)$ \\
\hline$>0.5-1.0$ & $12(28)$ \\
\hline$>1.0-2.0$ & $8(19)$ \\
\hline$>2.0$ & I (2) \\
\hline Node-positive & $4(9)$ \\
\hline \multicolumn{2}{|l|}{ Grade of invasive cancers } \\
\hline । & $3(\mid 1)$ \\
\hline 2 & $16(57)$ \\
\hline 3 & $9(32)$ \\
\hline Hormone receptor-positive & $19(63)$ \\
\hline \multicolumn{2}{|l|}{ Treatment and follow-up $(n=41)$} \\
\hline Adjuvant chemotherapy given & $13(32)$ \\
\hline Median years since diagnosis, overall (range) & $8.1(2.2-13)$ \\
\hline Prevalent cancers & $8.7(3-13)$ \\
\hline Incident cancers & $6.6(2.2-12)$ \\
\hline Local recurrence/new primary ${ }^{f}$ & $3(18)$ \\
\hline Metachronous contralateral cancer & 0 \\
\hline Distant recurrence & I (2) \\
\hline \multicolumn{2}{|l|}{ Survival status } \\
\hline Death, breast cancer & | (2) \\
\hline Death, other cause ${ }^{g}$ & $3(7)$ \\
\hline Alive, cancer-free & $37(90)$ \\
\hline
\end{tabular}

Abbreviations: DCIS, ductal carcinoma in situ; $\mathrm{MRI}=$ magnetic resonance imaging aEthnicity was indicated by each participant on the intake questionnaire and refers to either parental background. ${ }^{b}$ Tamoxifen use for chemoprophylaxis only. ${ }^{\text {T Total of }} 43$ cancers (2 participants with synchronous bilateral disease). ${ }^{\mathrm{d}}$ No neoadjuvant chemotherapy was given. Two invasive tumours were HER2neu-positive. ${ }^{\mathrm{F}}$ Four women who died are excluded. ${ }^{\mathrm{f}} \mathrm{A}$ total of 17 women initally chose breast-conserving therapy. On follow-up, seven eventually went on to have bilateral mastectomy. ${ }^{g}$ Other deaths due to suicide, ovarian cancer, and primary peritoneal cancer.

cancers (2\%), a very high proportion of early stage incident cancers $(97 \%)$, and a distant recurrence rate of $3.6 \%$ after a median follow-up of over 8 years. On the basis of these results, we recommend annual screening with MRI for women with a $B R C A 1$ or BRCA2 mutation who have not undergone prophylactic mastectomy.

In a Dutch trial of MRI screening for high-risk women, conducted from 1999 to 2006, 47 cancers were found among 594 previously unaffected $B R C A$ mutation carriers (Rijnsburger et al, 2010). They reported sensitivities of $71 \%$ and $41 \%$ for MRI and mammography, respectively. In their sensitivity analysis, interval cancers diagnosed within the 1-year period following the last screen were included, but incidental cancers identified at prophylactic mastectomy were excluded. For the period from 2003 to 2009, our sensitivity estimate was $94 \%$ for MRI, compared with $9 \%$ for mammography (if we were to exclude the incidental cancers found at prophylactic mastectomy, then MRI sensitivity would be $100 \%$ for this time period). The reason for the discrepancy between the two studies is unclear. Technological innovation, operator and/or radiologist expertise, and patient age may have impacted on MRI sensitivity. Despite a median age at cancer diagnosis of 45 years (range 27 to 68 years) in the Dutch study that was similar to our cohort of unaffected carriers (median 46 years, range 32 to 68 years), $3 B R C A 1$ mutation carriers under the age of 30 were diagnosed with cancer in the Dutch trial, whereas no cancers were diagnosed in this age group in our study. As tumour growth is more rapid in younger $B R C A 1$ mutation carriers (Tilanus-Linthorst et al, 2007), this may have contributed to their higher interval cancer rate. The UK MARIBS study was another large multicentre MRI screening study of 649 high-risk women, including $120 B R C A$ mutation carriers (MARIBS study group, 2005). Median enrolment age was 40 years (range 31 to 55 years), and reported overall sensitivities for MRI and mammography were $77 \%$ and $40 \%$, respectively, with an interval cancer rate of $6 \%$. Recurrence and survival data have not yet been reported.

We noted improvement in the sensitivity of MRI over the course of our study. A decline in the sensitivity of mammography is to be expected as the sensitivity of MRI improves, because very small MRI-detected cancers are difficult to detect with mammography. Indeed, the average size of MRI-detected lesions was greater in the period from 1997 to 2002, compared with those detected from 2003 to $2009(1.16 v s 0.77 \mathrm{~cm})$. In a recent paper from the UK, the sensitivity of mammography was reported to be $77 \%$ for screening high-risk women (FH01 Collaborative Teams, 2010), far better than the sensitivity of $9 \%$ reported here. The enormous difference is a consequence of different protocols; in the UK study, subjects received mammography only, while in our study, subjects also underwent MRI screening (i.e., sensitivity is not a fixed quantity, but is context-dependent). In the absence of an MRI facility, we support the use of mammography as a screening tool. However, our current data does not support the use of film mammography in addition to MRI screening. Digital mammography was introduced towards the end of the study (January 2008), and it is too early to say what the impact on sensitivity would be.

We found MRI to be equally effective in the screening of women with $B R C A 1$ and $B R C A 2$ mutations. In the Dutch study, MRI was more sensitive than mammography for detecting tumours in $B R C A 1$ mutation carriers, but not in BRCA2 carriers. Contributing factors could be differences in the mammographic appearance of cancers in the two subgroups, a higher growth rate in BRCA1associated cancers, or a higher proportion of non-invasive cancers among BRCA2 carriers (Kuhl et al, 2007; Gilbert et al, 2009). In our study, $26 \%$ of all cancers in BRCA1 carriers and $46 \%$ of cancers in $B R C A 2$ carriers were DCIS. In BRCA1 carriers, $38 \%$ of DCIS cases had evidence of micro-invasion, compared with $8 \%$ of DCIS cases in $B R C A 2$ carriers, suggesting that tumours in $B R C A 1$ carriers may become invasive earlier than those in BRCA2 carriers. Some studies suggest that $B R C A 1$-associated cancers grow faster than $B R C A 2$-related breast cancers, and the authors have suggested that the screening interval may need to be shorter for $B R C A 1$ carriers than for BRCA2 carriers (Tilanus-Linthorst et al, 2007; Shah et al, 2009 ). In the Dutch cohort, $32 \%$ of the cancers in $B R C A 1$ carriers and $6 \%$ of the cancers in BRCA2 carriers presented as interval cancers. In our study, only one interval cancer was detected in a $B R C A 1$ carrier, yielding a $3 \%$ interval cancer rate in the $B R C A 1$ group. As noted above, the difference in interval cancer rate between the two studies may be partly related to the younger age of cancer detection in the Dutch BRCA1 cohort ( 3 under 30 years of age). On the basis of a low interval cancer rate, our study does not support shortening the screening interval for either subgroup. 
In our study, the sensitivity of MRI varied little with age. Notably, the sensitivity of mammography was poor in women over the age of $50(16 \%)$, despite the anticipated decline in breast density associated with increasing age. These results support the recommendation that women with a $B R C A$ mutation should continue to receive annual MRI screening beyond age 50 , in contrast to screening guidelines in the UK (National Institute for Health and Clinical Excellence (NICE), 2006). A prior detailed analysis of mammographic sensitivity based on breast density in $B R C A$ mutation carriers revealed that, although there was a trend towards greater mammographic sensitivity for invasive cancers (not DCIS) in women with less dense breasts compared to women with greater breast density $(37-43 \%$ vs $8-12 \%$; $P=0.1)$, the sensitivity of mammography was still inadequate in the former group (Bigenwald et al, 2008). This study is unable to address the issue of whether the MRI screening interval can be increased in older women (with recommended age-based intervals possibly varying between $B R C A 1$ and $B R C A 2$ mutation carriers).

Our data do not provide evidence to base a recommendation for when MRI screening should be stopped, but age and life expectancy of the individual woman are factors to consider. Our data support the recommendation that MRI screening be performed routinely from age 30 onwards. No cancer was identified in a woman below age 30. Furthermore, of the cancers detected at the first round of screening, the youngest age of diagnosis of a large $(>2 \mathrm{~cm})$ or node-positive cancer was 48 years. This observation suggests that if screening were initiated at age 30 and done annually thereafter, most advanced or node-positive cancers could be avoided. However, our study did not have sufficient power to rule out a benefit for screening women aged 25-29 who have a family history of very early-onset breast cancer.

It is unclear how many of the 20 cases of DCIS diagnosed in this study represent over-diagnosis, but at the very least, the four with micro-invasion were likely of clinical significance. Longer followup of larger numbers of $B R C A$ mutation carriers undergoing MRI screening matched to an appropriate control group would be needed to determine the degree to which the increased detection of DCIS lowers the subsequent incidence of invasive disease.

The Dutch MRI study is the only other high-risk MRI screening trial to report on long-term outcomes in their screened women (Rijnsburger et al, 2010). In their study, 4 of the 42 mutation carriers diagnosed with an invasive cancer in the screening cohort died of their disease and 1 more had developed metastatic disease. They report an $84 \%$ distant disease-free survival rate at 6 years and an annual mortality rate of $1.2 \%$. In our study, with a follow-up time of 8 years, only one distant recurrence and death occurred in a woman who was diagnosed with cancer on her first screen at age
48. This is equivalent to an annual mortality rate for invasive cancers of $0.5 \%$. This estimate may be conservative, as we excluded micro-invasive disease from the survival analysis. Our results are very encouraging, particularly in view of the predilection of 'triplenegative' cancers, which constituted $43 \%$ of the cancers in our study, to relapse early (Dent et al, 2009). However, for both studies, the sample size is not very large and the follow-up period still relatively short. Moreover, it is not known whether the Canadian or Dutch experience better represents the outcome of screening high-risk women in a non-study setting in 2012. One limitation of our study is that $7 \%$ of the screened cohort was lost to follow-up. However, none of the 54 women diagnosed with cancer on study were lost to follow-up, and thus, our reporting of relapse and mortality for this group is accurate.

In conclusion, our study suggests that MRI surveillance of women with $B R C A$ mutations performed at an experienced centre, beginning at age 30 , detects the majority of breast cancers at an early stage, yielding a low rate of distant relapse at 8.4 years followup. These results are encouraging and suggest that MRI surveillance may be a safe alternative to prophylactic mastectomy for women with $B R C A$ mutations who can tolerate the high risk of a future breast cancer diagnosis, but longer-term follow-up data is needed.

\section{ACKNOWLEDGEMENTS}

We thank all of the women who participated in the study. This work was supported by the Canadian Breast Cancer Research Alliance (Grant number 012345).

\section{Conflict of interest}

DP was a former stockholder in Sentinelle Medical and is a current shareholder in General Electric (both companies make MRI equipment). PC is a member of the Bayer Gadovist and Sentinelle Medical Breast Imaging Advisory Boards. EW has sat on the Bayer Schering Pharma Advisory Board in the past 3 years. All other authors declare no conflict of interest.

\section{Disclaimer}

The funding source did not have any involvement in the design of the study; the collection, analysis, and interpretation of the data; the writing of the manuscript; or the decision to submit the manuscript for publication.

\section{REFERENCES}

Antoniou A, Pharoah PDP, Narod S, Risch HA, Eyfjord JE, Hopper JL, Loman N, Olsson H, Johannsson O, Borg A, Pasini B, Radice P, Manoukian S, Eccles DM, Tang N, Olah E, Anton-Culver H, Warner E, Lubinski J, Gronwald J, Gorski B, Tulinius H, Thorlacius S, Eerola H, Nevanlinna H, Syrjäkoski S, Kallioniemi O-P, Thompson D, Evans C, Peto J, Lalloo F, Evans DG, Easton DF (2003) Average risk of breast and ovarian cancer associated with BRCA1 or BRCA2 mutations detected in case series unselected for family history: a combined analysis of 22 studies. Am J Hum Genet 72: 1117-1130

Bigenwald RZ, Warner E, Gunesakar A, Hill KA, Causer PA, Messner SJ, Eisen A, Plewes DB, Narod SA, Zhang L, Yaffe MJ (2008) Is mammography adequate for screening women with inherited mutations and low breast density? Cancer Epidemiol Biomarkers Prev 17: 706-711

Chen S, Parmigiani G (2007) Meta-analysis of BRCA1 and BRCA2 penetrance. J Clin Oncol 25: 1329-1333

Daniel BL, Birdwell RL, Butts K, Nowels KW, Ikeda DM, Heiss SG, Cooper CR, Jeffrey SS, Dirbas FM, Herfkens RJ (2001) Freehand iMRI-guided large-gauge core needle biopsy: a new minimally invasive technique for diagnosis of enhancing breast lesions. J Magn Reson Imaging 13: 896-902

Dent R, Hanna WM, Trudeau M, Rawlinson E, Sun P, Narod SA (2009) Time to disease recurrence in basal-type breast cancers: effects of tumour size and lymph node status. Cancer 115: 4917-4923

FH01 Collaborative Teams (2010) Mammographic surveillance in women younger than 50 years who have a family history of breast cancer: tumour characteristics and projected effect on mortality in the prospective, single arm, FH01 study. Lancet Oncol 11: 1127-1134

Gilbert FJ, Warren RM, Kwan-Lim G, Thompson DJ, Eeles RA, Evans DG, Leach MO (2009) Cancers in BRCA1 and BRCA2 carriers in women at high risk for breast cancer: MR imaging and mammographic features. Radiology 252: 358-368

Hagen AI, Kvistad KA, Maehle L, Holmen MM, Aase H, Styr B, Vabø A, Apold J, Skaane P, Møller P (2007) Sensitivity of MRI versus conventional screening in the diagnosis of BRCA-associated breast cancer in a national prospective series. Breast 16: 367-374 
Hartmann LC, Schaid DJ, Woods JE, Crotty TP, Myers JL, Arnold PG, Petty PM, Sellers TA, Johnson JL, McDonnell SK, Frost MH, Jenkins RB (1999) Efficacy of bilateral prophylactic mastectomy in women with a family history of breast cancer. $N$ Engl J Med 340: 77-84

Kopans DB, D'Orsi CJ, Adler DD et al. (1993) American College of Radiology (ACR): Breast Imaging Reporting and Data System (BI-RADS). 2nd edn pp, 15-18. American College of Radiology: Reston, Virginia

Kriege M, Brekelmans CTM, Boetes C, Besnard PE, Zonderland HM, Obdeijn IM, Manoliu RA, Kok T, Peterse H, Tilanus-Linthorst MMA, Muller SH, Meijer S, Oosterwijk JC, Beex LVAM, Tollenaar RAEL, de Koning HJ, Rutgers EJT, Klijn JGM (2004) Efficacy of MRI and mammography for breast-cancer screening in women with a familial or genetic predisposition. $N$ Engl J Med 351: 427-437

Kuhl CK, Schrading S, Leutner CC, Morakkabati-Spitz N, Wardelmann E, Fimmers R, Kuhn W, Schild HH (2005) Mammography, breast ultrasound, and magnetic resonance imaging for surveillance of women at high familial risk for breast cancer. J Clin Oncol 23: 8469-8476

Kuhl CK, Schrading S, Bieling HB, Wardelmann E, Leutner CC, Koenig R, Kuhn W, Schild HH (2007) MRI for diagnosis of pure ductal carcinoma in situ: a prospective observational study. Lancet 370: 485-492

Lehman C, Blume JD, Weatherall P, Thickman D, Hylton N, Warner E, Pisano E, Schnitt SJ, Gatsonis C, Schnall M (2005) Screening women at high risk for breast cancer with mammography and magnetic resonance imaging. Cancer 103: 1898-1905

Lehman CD, Isaacs C, Schall MD, Pisano ED, Ascher SM, Weatherall PT, Bluemke DA, Bowen DJ, Marcom PK, Armstrong DK, Domchek SM, Tomlinson G, Skates SJ, Gatsonis C (2007) Cancer yield of mammography, MR, and US in high-risk women: prospective multi-institution breast cancer screening study. Radiology 244: 381-388

MARIBS Study Group (2005) Screening with magnetic resonance imaging and mammography of a UK population at high familial risk of breast cancer: a prospective multicentre cohort study (MARIBS). Lancet 365: $1769-1778$

National Institute for Health and Clinical Excellence (NICE) (2006) Familial Breast Cancer: the classification and care of women at risk of familial breast cancer in primary, secondary and tertiary care. Available at http://www.nice.org.uk/nicemedia/live/10994/30244/30244.pdf

Rijnsburger AJ, Obdeijn I, Kaas R, Tilanus-Linthorst MMA, Boetes C, Loo CE, Wasser MNJM, Bergers E, Kok T, Muller SH, Peterse H, Tollenaar RAEM, Hoogerbrugge N, Meijer S, Bartels CCM, Seynaeve C, Hooning MJ, Kriege M, Schmitz PIM, Oosterwiik JC, de Koning HJ, Rutgers EJT, Klijn JGM (2010) BRCA1-associated breast cancers present differently from BRCA2-associated and familial cases: long-term follow-up of the Dutch MRISC screening study. J Clin Oncol 28: 5265-5273

Sardanelli F, Podo F, Santoro F, Manoukian S, Bergonzi S, Trecate G, Vergnaghi D, Federico M, Cortesi L, Corcione S, Morassut S, Di Maggio C, Cilotti A, Martincich L, Calabrese M, Zuiani C, Preda L, Bonanni B, Carbonaro LA, Contegiacomo A, Panizza P, Di Cesare E, Savarese A, Crecco M, Turchetti D, Tonutti M, Belli P, Del Maschio A (2011) Multicentre surveillance of women at high genetic breast cancer risk using mammography, ultrasonography, and contrast-enhanced magnetic resonance imaging (the HIBCRIT-1 study): final results. Invest Radiol 46: 94-105

Shah P, Rosen M, Stopfer J, Siegfried J, Kaltman R, Mason B, Armstrong K, Nathanson KL, Schnall M, Domchek SM (2009) Prospective study of breast MRI in BRCA1 and BRCA2 mutation carriers: effect of mutation status on cancer incidence. Breast Cancer Res Treat 118: 539-546

Tilanus-Linthorst MMA, Obdeijn I-M, Hop WCJ, Causer PA, Leach MO, Warner E, Pointon L, Hill K, Klijn JGM, Warren RML, Gilbert FJ (2007) A BRCA1 mutation and young age predict fast breast cancer growth in the Dutch, UK, and Canadian MRI screening trials. Clin Cancer Res 13: 7357-7362

Warner E, Plewes DB, Hill KA, Causer PA, Zubovits JT, Jong RA, Cutrara MR, DeBoer G, Yaffe MJ, Messner SJ, Meschino WS, Piron CA, Narod SA (2004) Surveillance of BRCA1 and BRCA2 mutation carriers with magnetic resonance imaging, ultrasound, mammography, and clinical breast examination. JAMA 292: 1317-1325

Warner E, Messersmith H, Causer P, Eisen A, Shumak R, Plewes D (2008) Systematic review: using magnetic resonance imaging to screen women at high risk for breast cancer. Ann Intern Med 148: 671-679

This work is published under the standard license to publish agreement. After 12 months the work will become freely available and the license terms will switch to a Creative Commons Attribution-NonCommercial-Share Alike 3.0 Unported License. 